\title{
TRANSMISSION AND CONVERSION ELECTRON MÖSSBAUER STUDY OF CRYSTALLIZATION OF AMORPHOUS FeZrB ALLOYS
}

\author{
A. Grabias and M. Kopcewicz
}

Institute of Electronic Materials Technology, Wólczyńska 133, 01-919 Warszawa, Poland

The combined conversion electron emission and $\gamma$-transmission Mössbauer spectroscopy are used to investigate the differences in the bulk and surface crystallization of the amorphous FeZrB alloy in which the nanocrystalline bcc-Fe phase was formed due to annealing. The measurements were performed for the ribbons in the as-quenched state, after $1 \mathrm{~h}$ annealing at $430-600^{\circ} \mathrm{C}$ and after short time annealing at $600^{\circ} \mathrm{C}$. The clear differences in the surface and bulk crystallization behaviours were detected. Not only the surface crystallization starts at lower annealing temperature than the bulk one, but additional phases were detected at the surface which do not form in the bulk. Structural transformations as a function of annealing time (15-120 s) are compared with those induced by $1 \mathrm{~h}$ anneals. The enhanced surface crystallization was attributed to the boron depletion of the surface region which leads to the decrease in the crystallization temperature at the surface.

PACS numbers: $76.80 .+\mathrm{y}, 75.50 . \mathrm{Kj}, 75.50 . \mathrm{Bb}, 81.40 .-\mathrm{z}$

\section{Introduction}

The nanocrystalline bcc-Fe phase is formed in the amorphous precursor due to the controlled crystallization at temperatures in the range of $500-650^{\circ} \mathrm{C}$, i.e., at temperatures between the first and second exothermic peaks in the differential scanning calorimetry (DSC) curve [1, 2]. Annealing at higher temperature, exceeding that of the second DSC peak, causes dramatic deterioration of the soft magnetic properties due to the increase in the Fe-grain size and complete crystallization of the retained amorphous matrix [1,3]. A commonly used thermal processing of the amorphous FeZrB alloys, which leads to the formation of the nanocrystalline bcc-Fe phase consists in $1 \mathrm{~h}$ anneals at temperatures of $550-600^{\circ} \mathrm{C}$. However, technological thermal processing would greatly benefit from a less time-consuming process leading to the formation of the nanocrystalline structure with the required magnetic properties [4]. Therefore we examine the kinetics of the formation of such a phase in the amorphous $\mathrm{Fe}_{81} \mathrm{Zr}_{7} \mathrm{~B}_{12}$ alloy as a function of annealing time [5]. 
The formation of the bcc-Fe phase is studied by the Mössbauer spectroscopy. The transmission Mössbauer spectroscopy allows the identification of the nanocrystalline phase, the study of changes in the structure of the retained amorphous phase and the quantitative evaluation of the relative content of iron atoms in the nanocrystalline phase [2, 6-8]. The conversion electron Mössbauer spectroscopy (CEMS) permits a comparison between the crystallization products formed in the surface regions (about $100 \mathrm{~nm}$ thick) and those formed in the entire volume of the sample $[5,9]$.

In this paper, we report on CEMS and transmission Mössbauer studies of $\mathrm{Fe}_{81} \mathrm{Zr}_{7} \mathrm{~B}_{12}$ alloy in amorphous and nanocrystalline states. Structural transformations as a function of annealing time (15-120 s) are compared with those induced by $1 \mathrm{~h}$ anneals.

\section{Experimental details}

Amorphous $\mathrm{Fe}_{81} \mathrm{Zr}_{7} \mathrm{~B}_{12}$ ribbons, produced by the melt-spinning technique, were about $4 \mathrm{~mm}$ wide and $20 \mu \mathrm{m}$ thick. In order to obtain the nanocrystalline phase the amorphous ribbons were annealed for $1 \mathrm{~h}$ at temperatures $T_{\mathrm{A}}=$ $430-600^{\circ} \mathrm{C}$ and for $15,30,60,90$ and $120 \mathrm{~s}$ at $T_{\mathrm{A}}=600^{\circ} \mathrm{C}$.

The Mössbauer measurements were performed using a conventional constant acceleration spectrometer with a ${ }^{57} \mathrm{Co}$ in $\mathrm{Rh}$ source. The CEMS measurements were performed at room temperature using a gas-flow electron counter with $\mathrm{He}+\mathrm{CH}_{4}$ gas, in which the investigated sample was placed. A conventional proportional counter for measuring the transmitted $\gamma$-rays was placed behind the electron counter which was transparent to the $\gamma$-radiation. Thus, both transmission and CEMS measurements were performed simultaneously for the same part of the sample. Both sides of the samples (shiny and dull) were studied by CEMS.

The transmission and CEMS spectra of all annealed samples were fitted by combination of one or two hyperfine field distributions, $P\left(H_{\mathrm{hf}}\right)$, related to the retained amorphous and interfacial phases, with a discrete values of the hyperfine fields $\left(H_{\mathrm{hf}}\right)$ and isomer shifts $(\delta)$ corresponding to the bcc-Fe phase $\left(H_{\mathrm{hf}}=\right.$ $32.95 \mathrm{~T}, \delta=0.00 \mathrm{~mm} / \mathrm{s}$ ), and to the tetragonal $\mathrm{Fe}_{2} \mathrm{~B}$ (two components: $H_{\mathrm{hf} 1}=$ $23.2 \mathrm{~T}$ and $H_{\mathrm{hf} 2}=24.2 \mathrm{~T}$ and $\delta_{1}=0.12 \mathrm{~mm} / \mathrm{s}$ and $\delta_{2}=0.11 \mathrm{~mm} / \mathrm{s}$, respectively [10]). The $P\left(H_{\mathrm{hf}}\right)$ distributions were calculated by the histogram method [11]. using the NORMOS-DISTT program.

\section{Results and discussion}

\subsection{One-hour anneals as a function of annealing temperature}

As can be seen from Fig. 1, the transmission and CEMS spectra of the as-quenched $\mathrm{Fe}_{81} \mathrm{Zr}_{7} \mathrm{~B}_{12}$ alloy are similar. They consist of a broadened sextet due to hyperfine field distribution $P\left(H_{\mathrm{hf}}\right)$ (Fig. 1a"), characteristic of a purely amorphous state. However, clear differences between the bulk and surface crystallization appear already at $T_{\mathrm{A}}=430^{\circ} \mathrm{C}$. The transmission spectrum (Fig. 1b) consists of the spectral component characteristic of the purely amorphous state in which no crystalline phases could be detected, while the CEMS spectrum (Fig. $1 b^{\prime}$ ) reveals, 
beside that component, the magnetically split spectral component with the hyperfine field of about $33 \mathrm{~T}$ and $\delta=0.00 \mathrm{~mm} / \mathrm{s}$ characteristic of the bcc-Fe phase. Thus the crystallization process started already at $T_{\mathrm{A}}=430^{\circ} \mathrm{C}$ at the shiny surface of the sample. In the CEMS spectrum recorded for the dull side only traces of the bcc-Fe phase could be detected. The $P\left(H_{\mathrm{lff}}\right)$ distribution (Fig. $\left.1 \mathrm{~b}^{\prime \prime}\right)$ resembles the one characteristic of the as-quenched alloy. A similar situation was observed for

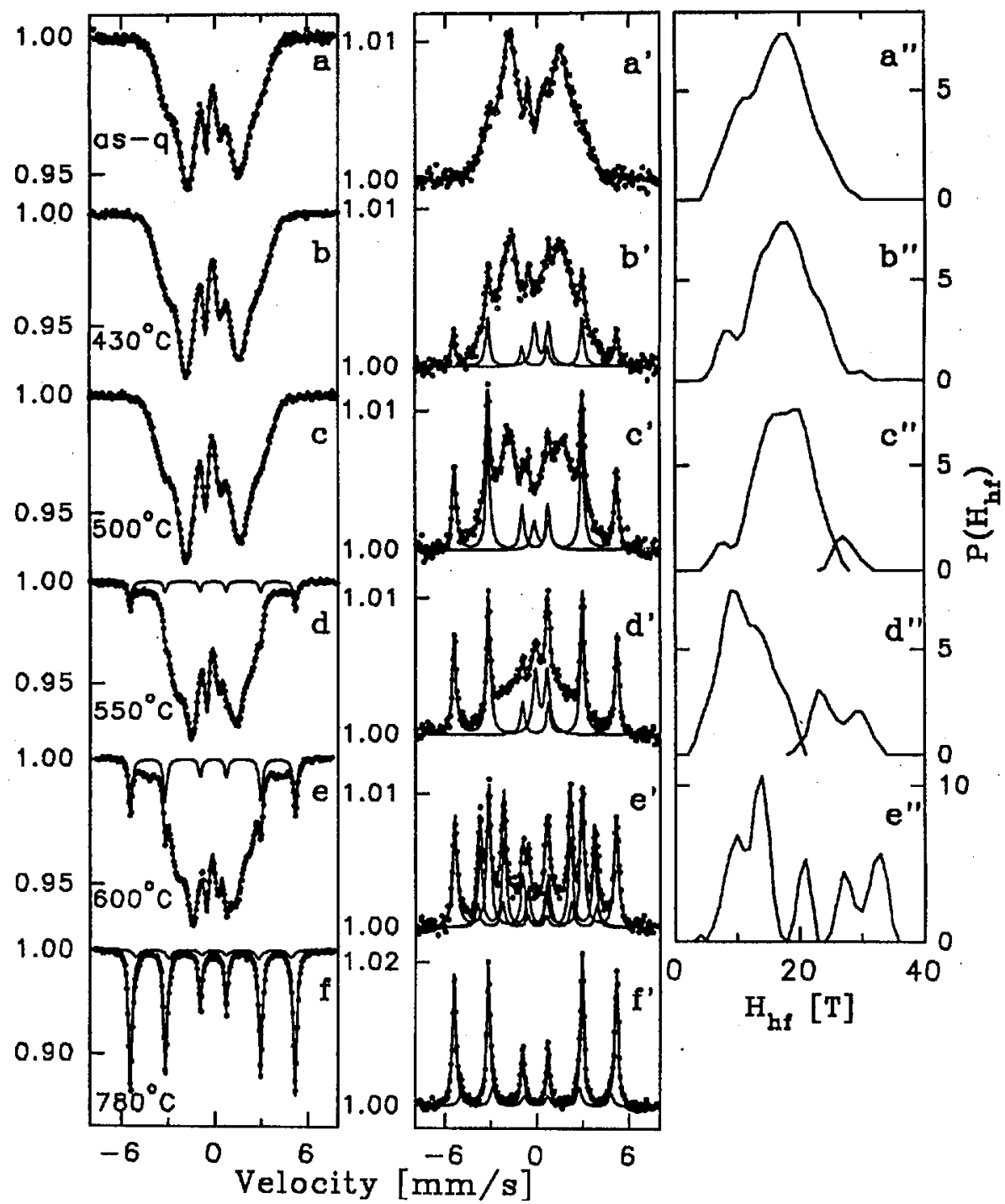

Fig. 1. Mössbauer transmission (a)-(f) and CEMS $\left(a^{\prime}\right)-\left(f^{\prime}\right)$ spectra and the corresponding $P\left(H_{\mathrm{hf}}\right)$ distributions $\left(\mathrm{a}^{\prime \prime}\right)-\left(\mathrm{f}^{\prime \prime}\right)$ for the as-quenched $\mathrm{Fe}_{81} \mathrm{Zr}_{7} \mathrm{~B}_{12}$ alloy (a, $\mathrm{a}^{\prime}$ ) and annealed for $1 \mathrm{~h}$ at indicated temperatures $\left((b)-(f)\right.$ and $\left.\left(b^{\prime}\right)-\left(f^{\prime}\right)\right)$. 
the sample annealed at $500^{\circ} \mathrm{C}$ (Figs. Ic and $\left.1 \mathrm{c}^{\prime}\right)$. However, the $P\left(H_{\mathrm{hf}}\right)$ distribution (Fig. $1 \mathrm{c}^{\prime \prime}$ ) consists now of two clear blocks: one, similar to that observed before (Fig. $1 \mathrm{a}^{\prime \prime}, 1 \mathrm{~b}^{\prime \prime}$ ) corresponding to the retained amorphous phase, and the second, much smaller appearing at $H_{\mathrm{hf}} \approx 28 \mathrm{~T}$, which can be attributed to the interfacial regions between the bcc-Fe nanograins and the amorphous matrix. Similar shape of the $P\left(H_{\mathrm{hf}}\right)$ was observed in Ref. [12].

The spectral contribution in CEMS spectrum of the sextet characteristic of bcc-Fe increases markedly with increasing annealing temperature. At $T_{\mathrm{A}}=$ $550^{\circ} \mathrm{C}$, which exceeds the $T_{x 1}$ temperature, the bcc-Fe phase appears in the bulk (Fig. 1d). The relative fraction of this phase is, however, much lower than that at the surface (Fig. $\left.1 \mathrm{~d}^{\prime}\right)$. In the $P\left(H_{\mathrm{hf}}\right)$ distribution (Fig. $1 \mathrm{~d}^{\prime \prime}$ ) extracted from the CEMS spectrum the peak in the first distribution block is shifted towards smaller $H_{\text {hf }}$ due to the decrease in $\mathrm{Fe}$ content in this phase: The relative contribution of the second block in $P\left(H_{\mathrm{hf}}\right)$ strongly increases. The $P\left(H_{\mathrm{hf}}\right)$ distribution, not shown in Fig. 1, extracted from the transmission spectra (Figs. 1a-1e) are dominated by a peak corresponding to the amorphous matrix, does not change markedly with increasing $T_{\mathrm{A}}$. However, also in these $P\left(H_{\mathrm{hf}}\right)$ distributions the interfacial component increases with the degree of crystallization.

In the CEMS spectra of the $\mathrm{Fe}_{81} \mathrm{Zr}_{7} \mathrm{~B}_{12}$ alloy annealed at $T_{\mathrm{A}}=430,500$ and $550^{\circ} \mathrm{C}$ beside the bcc-Fe sextet a paramagnetic component, not observed in any transmission spectra, consisting of the quadrupole splitting $(\mathrm{QS})$ doublet $(\mathrm{QS} \approx$ $0.80 \mathrm{~mm} / \mathrm{s}$ and $\delta \approx 0.34 \mathrm{~mm} / \mathrm{s}$ ) is clearly seen (Figs. $1 b^{\prime}-d^{\prime}$ ). The origin of this component is uncertain. However, the observed by us QS and $\delta$ values correspond quite well to those characteristic of the iron-poor paramagnetic amorphous $\mathrm{FeB}$ phase [13]. Such a phase could appear at the surface as a result of segregation of some iron atoms from the amorphous matrix to form the bcc-Fe phase. The amorphous $\mathrm{FeB}$ phase is unstable and decomposes with progressing crystallization. which occurs at higher annealing temperatures.

The CEMS spectrum of the $\mathrm{Fe}_{81} \mathrm{Zr}_{7} \mathrm{~B}_{12}$ sample annealed at $T_{\mathrm{A}}=600^{\circ} \mathrm{C}$ (Fig. $1 \mathrm{e}^{\prime}$ ) contains, in addition to the sextet characteristic of the bcc-Fe phase, very intense spectral components $\left(H_{\mathrm{hf} 1}=23.2 \mathrm{~T}\right.$ and $H_{\mathrm{hf} 2}=24.2 \mathrm{~T}$ and $\delta_{1}=$ $0.12 \mathrm{~mm} / \mathrm{s}$ and $\delta_{2}=0.11 \mathrm{~mm} / \mathrm{s}$, respectively) corresponding to the tetragonal $\mathrm{Fe}_{2} \mathrm{~B}$ phase [10] which contribute to about $40 \%$ of the total spectral area. This phase is formed only at the surface of the sample (on both shiny and dull sides). The transmission spectrum in Fig. 1e does not contain these spectral components.

Higher annealing temperature $\left(T_{\mathrm{A}}=780^{\circ} \mathrm{C}\right)$ causes complete bulk crystallization of the $\mathrm{Fe}_{81} \mathrm{Zr}_{7} \mathrm{~B}_{12}$ alloy. The amorphous phase disappears and the spectra, both transmission and CEMS, consist only of one sextet characteristic of the $\alpha$-Fe phase (Figs. If and $1 \mathrm{f}^{\prime}$ ) which suggests that iron atoms are separated from other alloy components.

The results discussed above are summarized in Fig. 2, which shows the relative abundance of various $\mathrm{Fe}$-containing phases detected in the transmission (Fig. 2a) and CEMS (Figs. 2b, 2c) spectra. The residual amorphous phase is at all annealing temperatures much more abundant in the bulk than at the surface. The CEMS results are presented for the shiny side (Fig. 2b) and the dull side (Fig. 2c). As can be seen, on the dull side the same phases appear at the same temperatures 


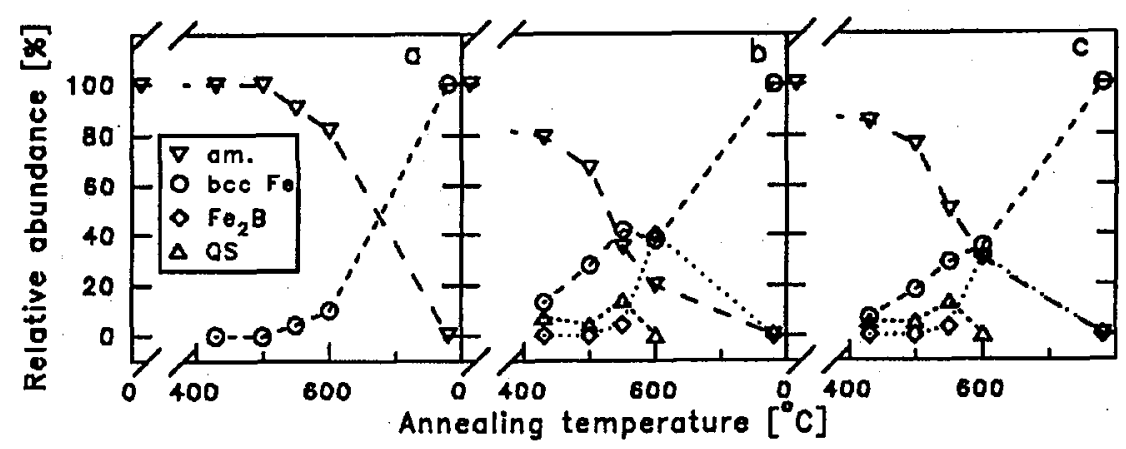

Fig. 2. Relative abundance of various phases vs. annealing temperature determined for the $\mathrm{Fe}_{81} \mathrm{Zr}_{7} \mathrm{~B}_{12}$ alloy (a) by transmission technique, (b) by CEMS (for shiny side) and (c) by CEMS (for dull side).

as on the shiny side, only their relative abundance is lower. The spectral contribution of the interfacial grain boundary component is somewhat larger at the surface . than in the bulk. The spectral contribution of the grain boundary component is directly related to the degree of crystallization and increases with increasing number of nanograins formed in the amorphous host. The grain boundary component was not included in Fig. 2. The onset of crystallization at the sample surface, occurring at lower annealing temperatures $\left(T_{\mathrm{A}}\right)$ than the bulk crystallization temperatures $\left(T_{x 1}\right)$, can be interpreted in a similar way as in earlier studies of the surface crystallization of conventional amorphous alloys [14, 15]. Most probably some boron atoms escape from the surface region during melt spinning process and during annealing. The decrease in boron content in the amorphous $\mathrm{Fe}_{81} \mathrm{Zr}_{7} \mathrm{~B}_{12}$ alloy decreases crystallization temperature as revealed by the DSC and Mössbauer measurements for $\mathrm{Fe}_{93-x-y} \mathrm{Zr}_{7} \mathrm{~B}_{x} \mathrm{Cu}_{y}$ alloys [8]. Hence, the crystalline phases, especially bcc-Fe, appear at the sample surface at lower $T_{\mathrm{A}}$ than in the bulk.

\subsection{Short time annealing at $600^{\circ} \mathrm{C}$}

The transmission and CEMS spectra recorded for the $\mathrm{Fe}_{81} \mathrm{Zr}_{7} \mathrm{~B}_{12}$ alloy annealed as a function of annealing time at $T_{\mathrm{A}}=600^{\circ} \mathrm{C}$ are shown in Fig. 3 together with the $P\left(H_{\mathrm{hf}}\right)$ distributions extracted from the corresponding spectra. The transmission spectra reveal the formation of the bcc-Fe phase in the bulk of the sample already after $15 \mathrm{~s}$ anneal (Fig. 3a) as evidenced by the appearance of the sextet with sharp lines. The relative contribution of this sextet is slightly larger for $1 \mathrm{~h}$ anneal (Fig. 3f) than after annealing for $60-120 \mathrm{~s}$ (Figs. 3c-3e). The $P\left(H_{\mathrm{hf}}\right)$ distributions, not shown in Fig. 3 , consist of a peak at about $14 \mathrm{~T}$ corresponding to the retained amorphous phase, and the second smaller peak at higher hyperfine fields (about 27-29 T) which is attributed to the interfacial regions between the bcc-Fe grains and the amorphous matrix in the same way as in the recent studies $[2,5,6,8,9]$. The relative atomic fractions of $\mathrm{Fe}$ as the amorphous, bcc-Fe and interfacial phases calculated from the transmission spectra presented in Fig. 3 are shown in Fig. 4a. The amorphous phase strongly dominates in the bulk and its spectral contribution saturates at about $80 \%$ for the sample annealed for $60 \mathrm{~s}$. The 


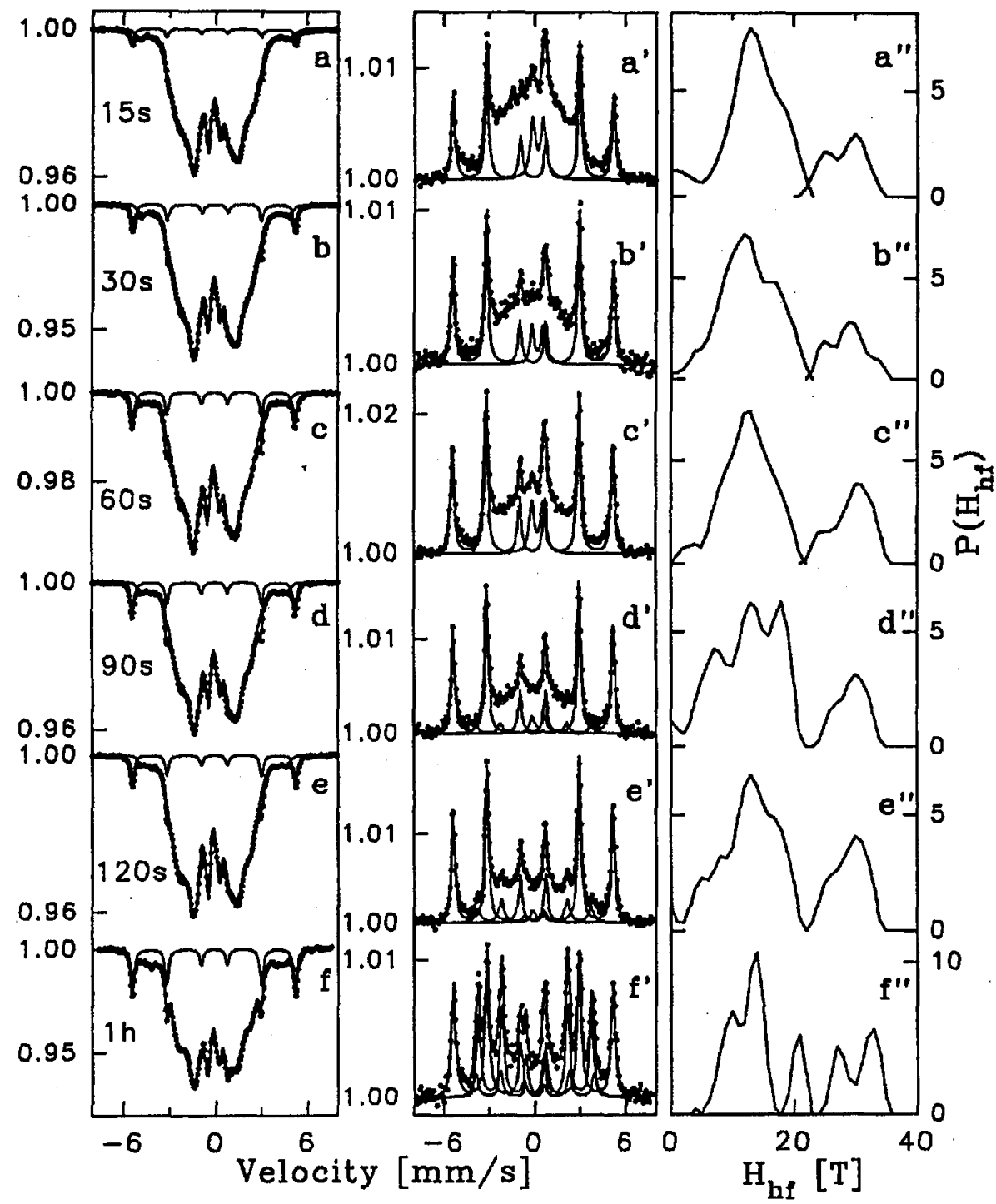

Fig. 3. Mössbauer transmission (a)-(f) and CEMS $\left(a^{\prime}\right)-\left(f^{\prime}\right)$ spectra and the corresponding $P\left(H_{\mathrm{hf}}\right)$ distributions $\left(\mathrm{a}^{\prime \prime}\right)-\left(\mathrm{f}^{\prime \prime}\right)$ for the $\mathrm{Fe}_{81} \mathrm{Z}_{7} \mathrm{~B}_{12}$ alloy annealed at $600^{\circ} \mathrm{C}$ for $15-120 \mathrm{~s}$ and for $1 \mathrm{~h}$.

relative content of the bcc-Fe phase increases with annealing time and saturates at about $8 \%$ after $60 \mathrm{~s}$ anneal.

The crystallization kinetics is studied by the CEMS technique, whose sampling depth is about $100 \mathrm{~nm}$. The CEMS spectra recorded for all annealed samples (Figs. $3 \mathrm{a}^{\prime}-3 \mathrm{f}^{f}$ ) clearly reveal much stronger surface than bulk crystallization (Figs. 3a-3f). The spectral component related to the amorphous matrix strongly decreases with the annealing time (Figs. $4 \mathrm{~b}, 4 \mathrm{c}$ ). The relative content of the bcc-Fe 


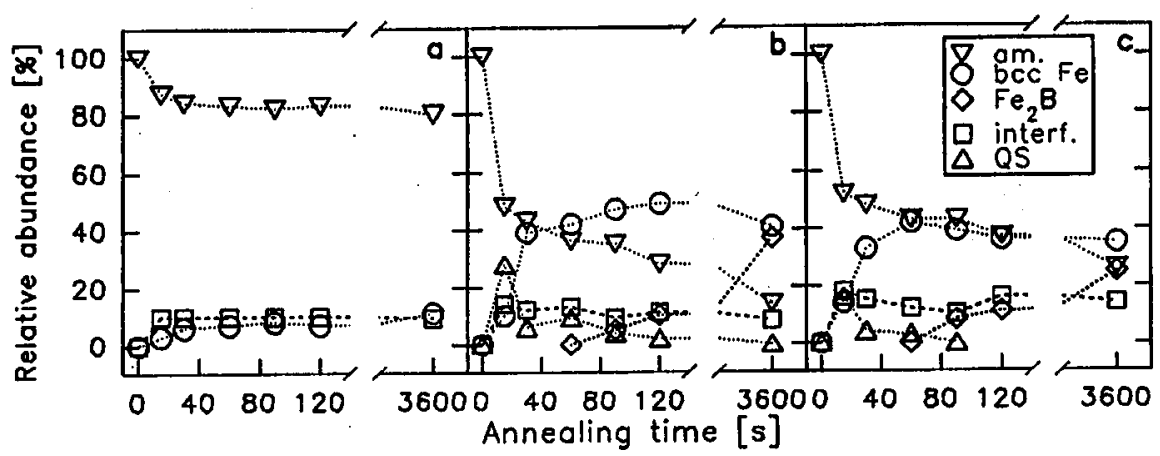

Fig. 4. Relative abundance of various phases vs. time of annealing determined for the $\mathrm{Fe}_{81} \mathrm{Zr}_{7} \mathrm{~B}_{12}$ alloy (a) by transmission technique, (b) by CEMS (for shiny side) and (c) by CEMS (for dull side).

phase increases dramatically for very short anneals ( 15 and $30 \mathrm{~s}$ ) and then almost saturates at about $40 \%$ after $60 \mathrm{~s}$ anneal (Figs. $4 \mathrm{~b}, 4 \mathrm{c}$ ). However, other phases, not observed in any transmission spectrum for bulk crystallization, appear at the sample's surfaces. In the CEMS spectra in Figs. $3 \mathrm{a}^{\prime}-3 \mathrm{c}^{\prime}$ a significant paramagnetic spectral component (a quadrupole doublet with the quadrupole splitting $\mathrm{QS}=0.80 \mathrm{~mm} / \mathrm{s}$ and $\delta=0.34 \mathrm{~mm} / \mathrm{s}$ ) similar to that in the spectra of $1 \mathrm{~h}$ annealed samples (Figs. $1 b^{\prime}-1 d^{\prime}$ ) is observed. It contributes to $28 \%$ (shiny side, Fig. $4 b$ ) or $16 \%$ (dull side, Fig. $4 \mathrm{c}$ ) for the sample annealed for $15 \mathrm{~s}$. The spectral contribution of this doublet decreases as annealing time increases and it disappears after $120 \mathrm{~s}$ and longer $(1 \mathrm{~h})$ anneals (Figs. $3 \mathrm{e}^{\prime}, 3 \mathrm{f}^{\prime}, 4 \mathrm{~b}, 4 \mathrm{c}$ ).

The amorphous phase is still retained in the sample annealed for $120 \mathrm{~s}$. Its spectral contribution decreases with annealing time to less than $40 \%$ (Figs. 4b, 4c). Two independent $P\left(H_{\mathrm{hf}}\right)$ distributions (Figs. $\left.3 \mathrm{a}^{\prime \prime}-3 \mathrm{f}^{\prime \prime}\right)$ were extracted from the broadened sextet in the CEMS spectra. The $P\left(H_{\mathrm{hf}}\right)$ ranging from 0 to about $20 \mathrm{~T}$ corresponds to the retained amorphous phase. The second $P\left(H_{\mathrm{hf}}\right)$ ranging from $20 \mathrm{~T}$ to about $35 \mathrm{~T}$, is attributed to the interfacial regions between the bcc-Fe grains and amorphous matrix. The relative content of the $\mathrm{Fe}$ atoms in the interfacial regions saturates at about $17 \%$ already after $30 \mathrm{~s}$ anneal and remains the same for longer annealing times (Figs. $4 \mathrm{~b}, 4 \mathrm{c}$ ). The change in the structure of the retained amorphous phase is clearly seen as the splitting of the single peak in the $P\left(H_{\mathrm{hf}}\right)$ distribution obtained for $15 \mathrm{~s}$ anneal (Fig. 3a") into several peaks when the abundance of the bcc-Fe phase increases (Figs. $3 \mathrm{~d}^{\prime \prime}-3 \mathrm{f}^{\prime \prime}$ ). This suggests strong composition fluctuations in the amorphous matrix due to progressing crystallization.

The qualitative changes observed in the transmission and CEMS spectra as a function of annealing time at $600^{\circ} \mathrm{C}$ are similar to those observed as a function of annealing temperature for $1 \mathrm{~h}$ anneals (Fig. 1). This means that the formation of a given phase is related to the degree of crystallization rather than to the annealing temperature alone.

The comparison of the CEMS spectra for the shiny and dull sides of the samples reveals that the amorphous matrix is less abundant at the shiny side. 


\section{Conclusions}

Our study shows the power of the combined CEMS and transmission Mössbauer spectroscopy for phase analysis in amorphous and nanocrystalline alloys. Clear differences between the surface and bulk crystallization behaviours were detected. The enhanced surface crystallization occurring at annealing temperatures lower than the bulk one was attributed to the boron depletion of the surface region which leads to the decrease in the crystallization temperature at the surface.

\section{Acknowledgments}

The amorphous $\mathrm{FeZrB}$ ribbons were kindly provided by the Department of Materials Science and Engineering at Warsaw University of Technology. This work was supported by the grant 2 P03B 06815 from the Committee for Scientific Research.

\section{References}

[1] K. Suzuki, A. Makino, A. Inoue, T. Masumoto, J. Appl. Phys. 70, 6232 (1991).

[2] M. Kopcewicz, A. Grabias, P. Nowicki, D.L. Williamson, J. Appl. Phys. 79, 993 (1996).

[3] K. Suzuki, J.M. Cadogan, V. Sahajwalla, A. Inoue, T. Masumoto, J. Appl. Phys. 79, 5149 (1996).

[4] T. Graf, M. Kopcewicz, J. Hesse, J. Phys., Condens. Matter 8, 3897 (1996).

[5] A. Grabias, M. Kopcewicz, Mater. Sci. Forum 269-272, 725 (1998).

[6] M. Miglierini, J.M. Greneche, J. Phys., Condens. Matter 9, 2321 (1997).

[7] P. Gorria, J.S. Garitaonandia, J.M. Barandiaran, J. Phys., Condens. Matter 8, 5925 (1996).

[8] M. Kopcewicz, A. Grabias, D.L. Williamson, J. Appl. Phys. 82, 1747 (1997).

[9] M. Kopcewicz, A. Grabias, J. Appl. Phys. 80, 3422 (1996).

[10] L. Takacs, M.C. Cadeville, I. Vincze, J. Phys. F 5, 800 (1975).

[11] J. Hesse, A. Rübartsch, J. Phys. E 7, 526 (1974).

[12] M. Miglierini, J.M. Greneche, J. Phys., Condens. Matter 9, 2303 (1997).

[13] W. Hoving, F. van der Woude, K.H.J. Buschow, in: Proc. Fifth Int. Conf. on Rapidly Quenched Metals, Eds. S. Steeb, H. Warlimont, North-Holland, Amsterdam 1985, p. 549.

[14] U. Gonser, M. Ackermann, H.G. Wagner, J. Magn. Magn. Mater. 31-34, 1605 (1983).

[15] H.N. Ok, A.H. Morrish, Phys. Rev. B 23, 2257 (1981). 